\title{
The Effects of Oral L-Carnitine Supplementation on Physical Capacity and Lipid Metabolism in Chronic Hemodialysis Patients
}

\author{
Yasuo Kudoh Shinya Aoyama Takaaki Torii Qijie Chen \\ Daigo Nagahara Hiromi Sakata Akihiko Nozawa
}

Kidney Center, Sapporo South One Hospital, Sapporo, Japan

\section{Key Words}

L-Carnitine · Physical capacity · Hemodialysis · Exercise test

\begin{abstract}
Background: It is well known that the physical activity in chronic hemodialysis patients decreases compared to that in normal subjects. In order to investigate the effects of L-carnitine on physical capacity and lipid metabolism, a cardiopulmonary exercise test using a bicycle ergometer was performed before and after 3 months of oral L-carnitine supplementation under double-blind conditions. Methods and Results: A total of 20 stable outpatients undergoing hemodialysis treatment were randomly divided into 2 groups: controls receiving placebo and patients receiving $900 \mathrm{mg}$ L-carnitine p.o. daily. The levels of free and acyl carnitine increased significantly from $22.9 \pm 7.3$ to $149.9 \pm 51.8 \mu \mathrm{mol} / \mathrm{l}$ and from $16.0 \pm 2.8$ to $100.3 \pm$ $50.2 \mu \mathrm{mol} / \mathrm{l}$, respectively, in the L-carnitine group; however, there was no significant change in other plasma lipid profiles. The exercise time was decreased and the heart rate at the anaerobic threshold was increased in the control group 3 months after the study period, but there were no such changes observed in the L-carnitine group. The minute ventilation $/ \mathrm{CO}_{2}$ output slope increased significantly from $38.9 \pm 7.8$ to $43.8 \pm 11.8$ in the L-carnitine group. It has been speculated that a shift in the energy source occurs from carbohydrate to lipid, in terms of an increase of oxygen demand. Conclusion: L-Carnitine supplementation might have some beneficial effects on the physical capacity of chronic hemodialysis patients due to the improvement of the lipid metabolism in the muscle.




\section{Introduction}

L-Carnitine is an essential factor for the membrane transport of acyl-CoA compounds, especially across the mitochondrial membrane and $\beta$-oxidation of lipid. L-Carnitine also regulates the acetyl-CoA/CoA ratio, thereby affecting the pyruvate dehydrogenase activity and the oxidation metabolism of glucose. Carnitine plays an additional role in the cell by removing potentially toxic organic acids by esterification forming acyl carnitine. Therefore, the role of carnitine in the cardiac and muscle metabolism might be highlighted in terms of energy production [1].

The concentration of L-carnitine in the plasma and tissue of chronic hemodialysis patients is decreased because of the impaired synthesis in the kidney and liver and the loss across the dialysis membrane during hemodialysis [2-4].

Muscle weakness is a common complication in hemodialysis patients. A positive correlation between muscle carnitine content and peak exercise performance has been reported in patients on chronic hemodialysis [5]. However, the benefit of L-carnitine treatment on muscle function and weakness is not established [2, 6-10]. Although the clinical assessment of symptomatology always presents serious problems of interpretation and reliability, studies that used more objective measures to evaluate the exercise capacity also revealed conflicting results $[2,6-10]$.

In order to clarify the effects of L-carnitine on the physical capacity and the lipid metabolism, CPX (a cardiopulmonary exercise test using a bicycle ergometer) was performed before and after 3 months of oral L-carnitine supplementation under double-blind conditions.

\section{Subjects and Methods}

\section{Subjects}

A total of 20 stable ambulatory hemodialysis patients were studied. The inclusion criteria were as follows: chronic hemodialysis for more than 2 years, unchanged dialysis frequency or duration for the previous 3 months, and stable laboratory data without severe anemia or hyperparathyroidism. Patients with diabetes and a prior myocardial infarction or a valvular heart disease were excluded. The patients were randomly assigned either to an active treatment group ( $900 \mathrm{mg}$ L-carnitine p.o. daily for 3 months) or a placebo group under doubleblind conditions. The hematological parameters of all patients were measured every month during the study period. The plasma levels of total and free carnitine were determined at baseline and at 3 months of the treatment period using the enzyme-cycling method. The study protocol was approved by the local Ethics Committee. Written informed consent was obtained from each patient.

\section{Cardiopulmonary Exercise Test Using a Bicycle Ergometer}

Exercise testing was performed just after hemodialysis at baseline and at 3 months of the treatment period. We adopted a ramp test in which the workload increased by $10 \mathrm{~W} / \mathrm{min}$ with pedaling at 50-60 rpm until fatigue occurred. Oxygen consumption $\left(\mathrm{VO}_{2}\right)$, carbon dioxide output $\left(\mathrm{VCO}_{2}\right)$, and minute ventilation (VE) were recorded continuously throughout the test using standard open-circuit spirometric procedures. The anaerobic threshold (AT) was calculated from the plots of $\mathrm{VO}_{2}$ against $\mathrm{VCO}_{2}$. The same technicians performed the $\mathrm{CPX}$ before and after the study period and were unaware of the treatment allocation. 
Fig. 1. Flow chart of patient allocation.

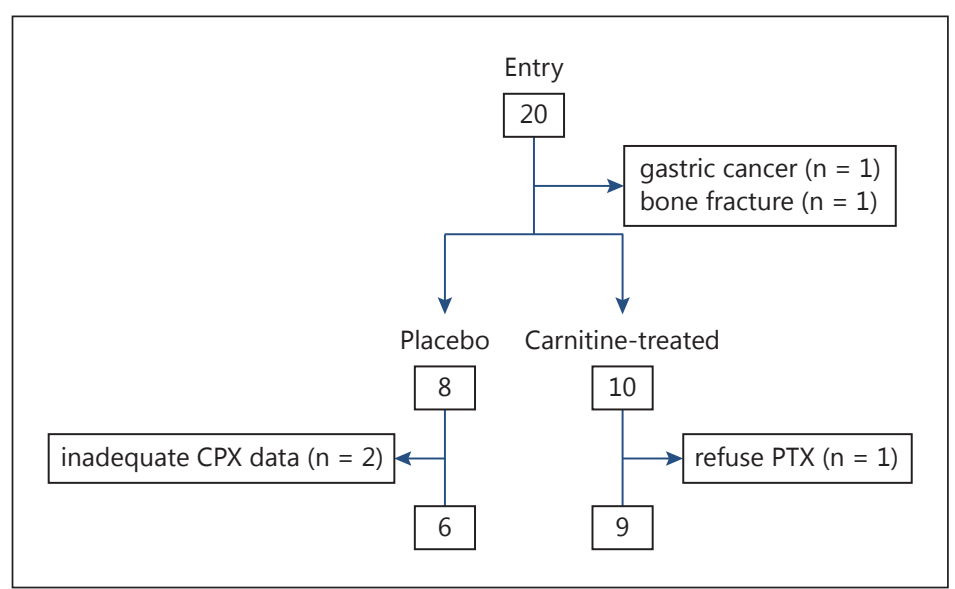

\section{Statistical Analysis}

Descriptive results are shown as the mean value \pm standard deviation. Data were statistically analyzed by Student's t test for paired or unpaired samples and the $\chi^{2}$ test. $p<0.05$ was regarded as significant.

\section{Results}

\section{Patient Allocation and Baseline Characteristics}

After randomization, 2 patients had to be excluded due to gastric cancer and an accidental bone fracture. A further 3 patients lacked adequate CPX data. Therefore a total of 15 patients were divided into a placebo group $(n=6)$ and a L-carnitine-treated group $(n=9$; fig. 1). There were no differences in the parameters examined between the placebo and the L-carnitine-treated group (table 1).

\section{Lipid Profile}

In the L-carnitine group, the levels of free and acyl carnitine were $22.9 \pm 7.3 \mu \mathrm{mol} / \mathrm{l}$ and $16.0 \pm 2.8 \mu \mathrm{mol} / \mathrm{l}$ at baseline, and $149.9 \pm 51.8 \mu \mathrm{mol} / \mathrm{l}$ and $100.3 \pm 50.2 \mu \mathrm{mol} / \mathrm{l}$ after $3 \mathrm{months}$, respectively. The difference in free carnitine levels at baseline versus after 3 months was highly significant $(\mathrm{p}<0.001)$, as was that in acyl carnitine levels at baseline versus after 3 months $(\mathrm{p}<0.001)$, representing a sixfold increment in both cases. In the L-carnitine group, the acyl/free carnitine ratio decreased significantly from $0.74 \pm 0.15$ at baseline to $0.65 \pm$ 0.13 after 3 months. There was a significant difference in the acyl/free carnitine ratio between the placebo and the L-carnitine-treated group after 3 months of L-carnitine supplementation $(\mathrm{p}<0.01)$. There were no significant changes in the plasma lipid concentrations (table 2).

\section{Effect of Oral L-Carnitine Treatment on CPX}

The exercise time decreased and the heart rate at AT increased in the control group after 3 months, but there were no such changes observed in the treated group (table 3). The VE/ $\mathrm{VCO}_{2}$ slope increased significantly from $38.9 \pm 7.8$ to $43.8 \pm 11.8$ in the treated group after 3 months ( $\mathrm{p}<0.05$; fig. 2). There were no significant differences in any CPX parameter between the control and treated group. 
Table 1. Patient characteristics

Kudoh et al.: The Effects of Oral L-Carnitine Supplementation on Physical Capacity and Lipid Metabolism in Chronic Hemodialysis Patients

\begin{tabular}{|c|c|c|c|}
\hline & $\begin{array}{l}\text { Placebo } \\
\text { group } \\
(n=6)\end{array}$ & $\begin{array}{l}\text { L-Carnitine- } \\
\text { treated group } \\
(\mathrm{n}=9)\end{array}$ & $\mathrm{p}$ value \\
\hline Age, years & $70.5 \pm 10.1$ & $66.2 \pm 7.1$ & 0.17 \\
\hline $\begin{array}{l}\text { Duration of dialysis, } \\
\text { months }\end{array}$ & $89.3 \pm 30.5$ & $162.2 \pm 127.9$ & 0.1 \\
\hline Males/females & $3 / 3$ & $3 / 6$ & 0.52 \\
\hline Total cholesterol, mg/dl & $150 \pm 26.5$ & $172.8 \pm 39.9$ & 0.12 \\
\hline Triglyceride, $\mathrm{mg} / \mathrm{dl}$ & $79.7 \pm 28.4$ & $103.3 \pm 79.2$ & 0.25 \\
\hline HDL cholesterol, mg/dl & $54.7 \pm 14.5$ & $61.1 \pm 20.9$ & 0.26 \\
\hline LDL cholesterol, mg/dl & $72.2 \pm 16.5$ & $82 \pm 33.5$ & 0.26 \\
\hline Apolipoprotein A1, mg/dl & $131.8 \pm 29.0$ & $144.9 \pm 29.1$ & 0.2 \\
\hline Apolipoprotein A2, mg/dl & $19.0 \pm 2.8$ & $22.1 \pm 4.2$ & 0.07 \\
\hline Apolipoprotein B, mg/dl & $61.7 \pm 12.6$ & $70.9 \pm 26.9$ & 0.23 \\
\hline Total carnitine, $\mu \mathrm{mol} / \mathrm{l}$ & $33.5 \pm 5.6$ & $38.9 \pm 9.7$ & 0.12 \\
\hline Free carnitine, $\mu \mathrm{mol} / \mathrm{l}$ & $19.3 \pm 5.0$ & $22.9 \pm 7.3$ & 0.16 \\
\hline Acyl carnitine, $\mu \mathrm{mol} / \mathrm{l}$ & $14.2 \pm 1.7$ & $16.0 \pm 2.8$ & 0.09 \\
\hline Acyl/free carnitine ratio & $0.77 \pm 0.16$ & $0.74 \pm 0.15$ & 0.37 \\
\hline Hematocrit, \% & $33.9 \pm 3.3$ & $34.3 \pm 2.9$ & 0.38 \\
\hline Hemoglobin, g/dl & $10.7 \pm 1.1$ & $10.9 \pm 1.1$ & 0.38 \\
\hline Serum Fe, $\mu \mathrm{g} / \mathrm{dl}$ & $86.2 \pm 15.3$ & $80.6 \pm 26.2$ & 0.32 \\
\hline Ferritin, ng/ml & $240.7 \pm 154.1$ & $208.7 \pm 240.2$ & 0.39 \\
\hline $\mathrm{BNP}, \mathrm{pg} / \mathrm{ml}$ & $264.3 \pm 162$ & $327.7 \pm 545.1$ & 0.39 \\
\hline Body weight, kg & $50.7 \pm 16.4$ & $51.9 \pm 11.6$ & 0.43 \\
\hline Statin therapy & $1 / 6$ & $0 / 9$ & 0.2 \\
\hline
\end{tabular}

Variables are presented as mean \pm SD or numbers.

$\mathrm{BNP}=$ Brain natriuretic peptide.

$\mathrm{p}$ values were calculated by a non-paired test or $\chi^{2}$ test. $\mathrm{p}<0.05$ was regarded as significant.

\section{Discussion}

\section{Physical Capacity and Assessment Method}

The total carnitine content in the muscle has been reported to be positively correlated with the exercise duration on the graded ergometer protocol, and the change in acyl carnitine content in the muscle with exercise was correlated with an increase in lactate content in the muscle of hemodialysis patients [5]. However, attempts to improve exercise performance in renal failure patients with carnitine therapy have not yielded consistent results [11-18]. Most of these trials used heterogeneous designs or assessment methods that have been poorly validated in dialysis patients.

Ahmad et al. [11] reported that the maximal oxygen consumption, measured during a progressive work exercise test, improved significantly and calculated a mid-arm muscle mass increase in their carnitine-treated group (20 mg/kg i.v. for 6 months). On the other hand, Brass et al. [12] reported that L-carnitine supplementation $(20 \mathrm{mg} / \mathrm{kg}$ i.v. for 6 months) increased the plasma carnitine concentrations in their study group, but did not affect the maximal oxygen consumption. After the administration of carnitine, an increase in total electromyography power was noted, suggesting that carnitine has a prevalent myotrophic effect [13]. An increased amplitude of the motor action potential and improved motor unit characteristics were reported [14]. Conflicting results were reported in another study, in which no significant changes in sensory and motor nerve conduction velocities or in vibration threshold 
Kudoh et al.: The Effects of Oral L-Carnitine Supplementation on Physical Capacity and Lipid Metabolism in Chronic Hemodialysis Patients

Table 2. Changes in lipid profiles

\begin{tabular}{|c|c|c|c|c|}
\hline & Baseline & After 1 month & After 2 months & After 3 months \\
\hline \multicolumn{5}{|l|}{ Placebo group } \\
\hline Total cholesterol, mg/dl & $149.7 \pm 26.5$ & $144.5 \pm 26.6$ & $143.8 \pm 28.1$ & $144 \pm 35.3$ \\
\hline Triglyceride, $\mathrm{mg} / \mathrm{dl}$ & $79.7 \pm 28.4$ & $64 \pm 20$ & $63.7 \pm 16.9$ & $71 \pm 22.5$ \\
\hline HDL cholesterol, mg/dl & $54.7 \pm 14.5$ & $53.7 \pm 13.1$ & $55.2 \pm 14.7$ & $54 \pm 12.2$ \\
\hline LDL cholesterol, mg/dl & $72.2 \pm 16.5$ & $65.7 \pm 17.5$ & $65.5 \pm 21$ & $67.7 \pm 27.4$ \\
\hline Apolipoprotein A1, mg/dl & $131.8 \pm 29$ & $129.3 \pm 25.8$ & $129.8 \pm 20.4$ & $126.2 \pm 19.1$ \\
\hline Apolipoprotein A2, mg/dl & $19.0 \pm 2.8$ & $19 \pm 1.6$ & $18.6 \pm 2.0$ & $18.3 \pm 2.2$ \\
\hline Apolipoprotein B, mg/dl & $61.7 \pm 12.6$ & $57.5 \pm 13.4$ & $53.5 \pm 11.8$ & $55.3 \pm 15.8$ \\
\hline Free carnitine, $\mu \mathrm{mol} / \mathrm{l}$ & $19.3 \pm 5.0$ & & & $18.4 \pm 3.2^{+++}$ \\
\hline Acyl carnitine, $\mu \mathrm{mol} / \mathrm{l}$ & $14.2 \pm 1.7$ & & & $15.3 \pm 3.3^{+++}$ \\
\hline Acyl/free carnitine ratio & $0.77 \pm 0.16$ & & & $0.83 \pm 0.10^{++}$ \\
\hline \multicolumn{5}{|l|}{ L-Carnitine-treated group } \\
\hline Total cholesterol, mg/dl & $172.8 \pm 39.9$ & $175.3 \pm 44.6$ & $172.6 \pm 36$ & $177.9 \pm 44.5$ \\
\hline Triglyceride, $\mathrm{mg} / \mathrm{dl}$ & $103.3 \pm 79.2$ & $108.2 \pm 73.1$ & $104.4 \pm 82.9$ & $103 \pm 44.4$ \\
\hline HDL cholesterol, mg/dl & $61.1 \pm 20.9$ & $58.6 \pm 21.7$ & $60 \pm 21.6$ & $60.1 \pm 21.2$ \\
\hline LDL cholesterol, mg/dl & $82.0 \pm 33.5$ & $82.9 \pm 29.8$ & $82.2 \pm 29.8$ & $90.8 \pm 34.8$ \\
\hline Apolipoprotein A1, mg/dl & $144.9 \pm 29.1$ & $148.3 \pm 33.7$ & $144.1 \pm 27.3$ & $145 \pm 29.3$ \\
\hline Apolipoprotein A2, mg/dl & $22.1 \pm 4.2$ & $30.0 \pm 20.9$ & $22.4 \pm 3.2$ & $23.7 \pm 3.6$ \\
\hline Apolipoprotein B, mg/dl & $70.9 \pm 26.9$ & $71.8 \pm 26.3$ & $67.7 \pm 21.6$ & $71 \pm 24.5$ \\
\hline Free carnitine, $\mu \mathrm{mol} / \mathrm{l}$ & $22.9 \pm 7.3$ & & & $149.9 \pm 51.8^{* * *,+++}$ \\
\hline Acyl carnitine, $\mu \mathrm{mol} / \mathrm{l}$ & $16.0 \pm 2.8$ & & & $100.3 \pm 50.2^{* * *,+++}$ \\
\hline Acyl/free carnitine ratio & $0.74 \pm 0.15$ & & & $0.65 \pm 0.13^{++}$ \\
\hline
\end{tabular}

Variables are presented as mean \pm SD.

$\mathrm{p}$ values were calculated by a non-paired t test or paired t test. $\mathrm{p}<0.05$ was regarded as significant.

*** $\mathrm{p}<0.001$ (baseline vs. after 3 months). ${ }^{++} \mathrm{p}<0.001$ (placebo group vs. L-carnitine-treated group). ${ }^{++} \mathrm{p}<0.01$ (placebo group vs. L-carnitine-treated group).

Table 3. Changes in the CPX data

\begin{tabular}{|c|c|c|}
\hline & Baseline & After 3 months \\
\hline \multicolumn{3}{|l|}{ Placebo group } \\
\hline $\mathrm{HR}$ at AT, beats/min & $99.3 \pm 17.3$ & $113.8 \pm 7.5^{*}$ \\
\hline $\mathrm{HR}$ at rest, beats/min & $87.5 \pm 14.7$ & $91.0 \pm 13.8$ \\
\hline \multicolumn{3}{|l|}{ HR at AT - HR at rest, } \\
\hline beats/min & $11.8 \pm 6.6$ & $22.8 \pm 12.7^{*}$ \\
\hline Load at AT, W & $38.5 \pm 17.0$ & $40.2 \pm 10.8$ \\
\hline Peak $\mathrm{VO}_{2}, \mathrm{ml} / \mathrm{kg} / \mathrm{min}$ & $11.8 \pm 3.7$ & $11.4 \pm 3.2$ \\
\hline $\mathrm{VE} / \mathrm{VCO}_{2}$ slope & $35.8 \pm 5.2$ & $37.8 \pm 6.7$ \\
\hline Exercise time, $\mathrm{s}$ & $184.0 \pm 78.0$ & $150.0 \pm 81.8^{*}$ \\
\hline \multicolumn{3}{|c|}{ L-Carnitine-treated group } \\
\hline $\mathrm{HR}$ at $\mathrm{AT}$, beats $/ \mathrm{min}$ & $99.7 \pm 24.6$ & $102.6 \pm 16.8$ \\
\hline $\mathrm{HR}$ at rest, beats/min & $82.7 \pm 19.2$ & $83.6 \pm 12.6$ \\
\hline \multicolumn{3}{|l|}{ HR at AT - HR at rest, } \\
\hline beats/min & $16.9 \pm 8.5$ & $19.0 \pm 15.2$ \\
\hline Load at AT, W & $33.9 \pm 11.9$ & $30.9 \pm 9.7$ \\
\hline Peak $\mathrm{VO}_{2}, \mathrm{ml} / \mathrm{kg} / \mathrm{min}$ & $11.9 \pm 3.1$ & $11.8 \pm 3.2$ \\
\hline $\mathrm{VE} / \mathrm{VCO}_{2}$ slope & $38.9 \pm 7.8$ & $43.8 \pm 11.8^{*}$ \\
\hline Exercise time, $\mathrm{s}$ & $120.3 \pm 63.2$ & $132.3 \pm 46.7$ \\
\hline
\end{tabular}


Kudoh et al.: The Effects of Oral L-Carnitine Supplementation on Physical Capacity and Lipid Metabolism in Chronic Hemodialysis Patients

Fig. 2. Changes in the $\mathrm{VE} / \mathrm{VCO}_{2}$ slope. ${ }^{*} \mathrm{p}<0.05$.
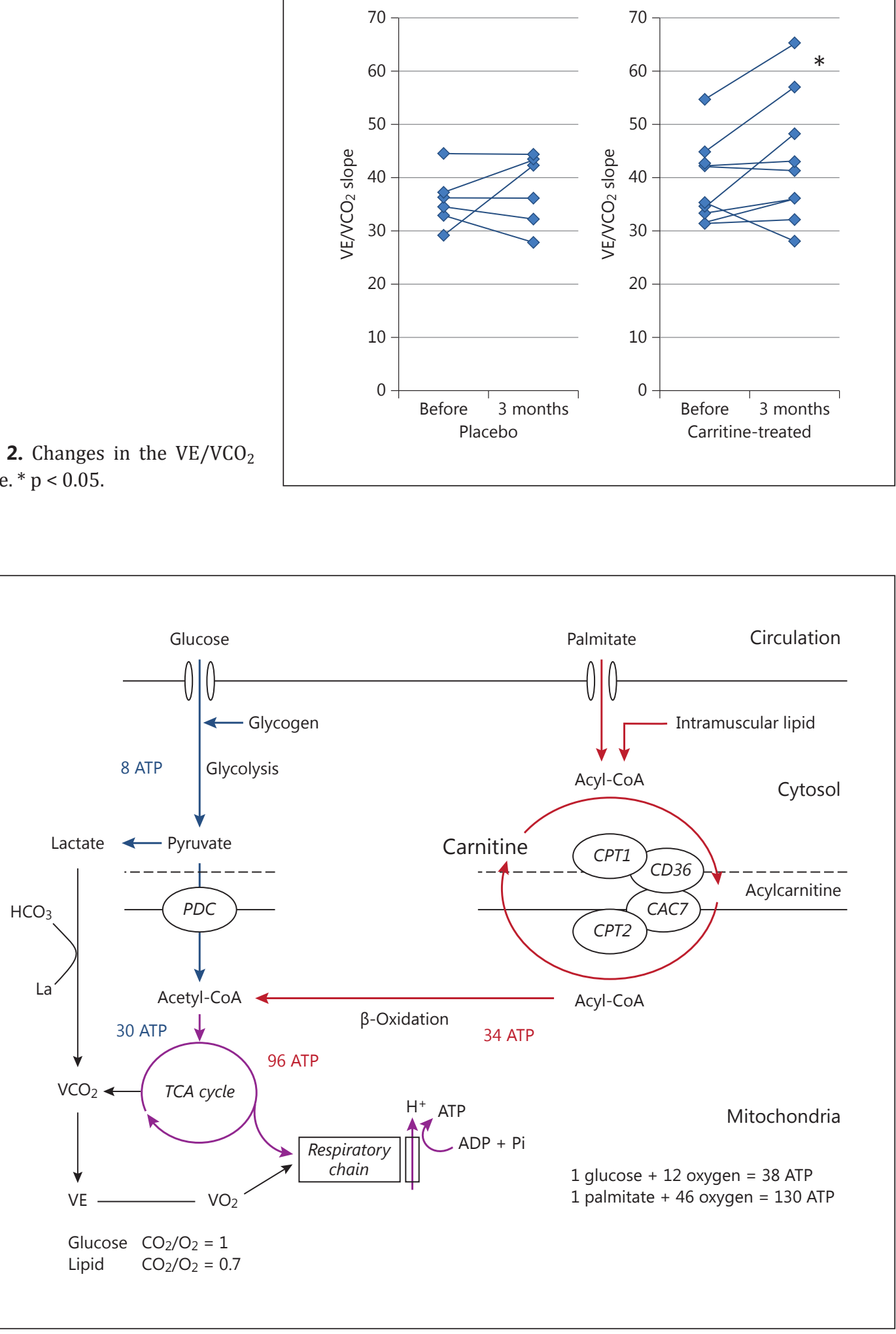

Fig. 3. Schema of energy efficiency. 
were noted after carnitine treatment [15]. Carnitine supplementation lowered serum myoglobin [16] and increased the diameter of type I and type IIa fibers by about 7\%, which can utilize carnitine for fatty-acid oxidation to produce energy [17]. However, Vaux et al. [18] reported that muscle bioenergetics failed to improve after carnitine administration $(20 \mathrm{mg} /$ kg i.v. for 16 weeks) using magnetic resonance spectroscopy and near-infrared spectroscopy.

As exercise capacity defines the range of physical activities that patients can accomplish, $\mathrm{CPX}$ can ultimately reflect the basic activities of independent living. In addition, peak $\mathrm{VO}_{2}$ has been shown to be an independent predictor of survival in a wide variety of clinical populations. Therefore, CPX was performed to assess the physical capacity in the present study. It is known that peak $\mathrm{VO}_{2}$ is influenced by sex, age, hemoglobin concentration and the diagnosis of diabetes [19], therefore, a randomized double-blind study design was applied.

\section{Peak $\mathrm{VO}_{2}$ and $\mathrm{VE} / \mathrm{VCO}_{2}$ Slope}

In the present study, the exercise time was decreased and the heart rate at AT was increased in the control group 3 months after the study period, but there were no such changes observed in the treated group (table 3). Fatouros et al. [20] reported that L-carnitine supplementation increased the time to fatigue and decreased post-exercise lactate. Peak $\mathrm{VO}_{2}$ has been considered a reliable prognostic variable in heart failure, associated with mortality. However, one must be cautious when interpreting the results, because this parameter highly depends on a patient's effort and interpatient variability is large. Recently, it has been reported that the $\mathrm{VE} / \mathrm{VCO}_{2}$ slope could be as powerful as peak $\mathrm{VO}_{2}$ in predicting serious cardiac events [21]. The $\mathrm{VE} / \mathrm{VCO}_{2}$ slope at submaximal workloads is easier to measure than peak $\mathrm{VO}_{2}$, and it does not rely on a subjective voluntary effort.

The VE/ $/ \mathrm{VCO}_{2}$ slope and leg muscle endurance percentage were reported to be significantly negatively related in patients with heart failure but not in normal subjects [22]. In contrast, elevations of the $\mathrm{VE} / \mathrm{VCO}_{2}$ slope were observed in patients with hyperventilation [23] or hyperthermia [24] as a result of an increase in VE. The carnitine concentration was reported to be positively correlated with the incorporation rate of palmitate-carbon into $\mathrm{CO}_{2}$ and the incorporation rate of glucose-carbon into lactate in the muscle tissue. These results indicate a coupling between the concentration of carnitine and the capacity for long-chain fatty-acid oxidation in human skeletal muscle [25]. It might be speculated that exogenous L-carnitine would result in an increased lipid oxidation and the sparing of muscle glycogen during submaximal exercise. One glucose molecule requires 12 oxygen atoms to produce 38 ATP molecules. The oxidation of 1 palmitate molecule produces 130 ATP molecules and requires 46 oxygen atoms. In this context, free fatty acids appear to be the most efficient substrate for energy production in terms of fuel supply, but they require more oxygen consumption [1] (fig. 3). In the present study, the $\mathrm{VE} / \mathrm{VCO}_{2}$ slope significantly increased from $38.9 \pm 7.8$ to $43.8 \pm 11.8$ in the treated group (fig. 2). This might indicate that a shift of energy source from carbohydrate to lipid increases the oxygen demand (fig. 3). One study [20] reported that $\mathrm{L}$-carnitine supplementation resulted in a reduction in the respiratory exchange rate, suggesting an increase in lipid oxidation and possible glycogen sparing, which is in agreement with our findings. L-Carnitine supplementation might have some beneficial effects on the physical capacity of chronic hemodialysis patients due to the improvement of the lipid metabolism in the muscle.

\section{Study Limitation}

In order to keep the patients' conditions constant (including their body weight and uremic toxin concentrations) during the exercise test, the CPX was performed just after the hemodialysis procedure. Although a strict study protocol was achieved, the sample size was relatively small in our study. 
In the present study, it is uncertain whether the period of administration ( 3 months) was long enough to demonstrate the maximal benefit for exercise capacity and symptoms. Although the carnitine concentration in the plasma increased significantly in our study, a final improvement of symptoms following the uptake of carnitine by depleted muscles and the consequent effect on metabolism may be much slower processes. A longer observation period might be necessary in future studies.

\section{Conclusion}

It is speculated that the L-carnitine supplementation might have some beneficial effects on the physical capacity of chronic hemodialysis patients due to the improvement of the lipid metabolism in the muscle.

\section{Disclosure Statement}

There is no conflict of interest.

\section{References}

1 Grynberg A, Demaison Ll: Fatty acid oxidation in the heart. J Cardiovasc Pharmacol 1996;28:S11-S17.

-2 Schreiber B: Levocarnitine and dialysis: a review. Nutr Clin Pract 2005;20:218-243.

-3 Bonomini M, Zammit V, Pusey CD, Vecchi AD, Arduini A: Pharmacological use of L-carnitine in uremic anemia: has its full potential been exploited? Pharmacol Res 2011;63:157-164.

4 Reuter SE, Evans AM: Carnitine and acylcarnitines. Pharmacokinetic, pharmacological and clinical aspects. Clin Pharmacokinet 2012;51:553-572.

5 Hiatt WR, Koziol BJ, Shapiro JI, Brass EP: Carnitine metabolism during exercise in patients on chronic hemodialysis. Kidney Int 1992;41:1613-1619.

6 Ahmad S: L-Carnitine in dialysis patients. Semin Dial 2001;14:209-217.

7 Hurot JM, Cucherat M, Haugh M, Fouque D: Effects of L-carnitine supplementation in maintenance hemodialysis patients: a systematic review. J Am Soc Nephrol 2002;13:708-714.

8 Pauly DF, Pepine CJ: The role of carnitine in myocardial dysfunction. Am J Kidney Dis 2003;41:S35-S43.

$\longrightarrow$ Hedayati SS: Dialysis-related carnitine disorder. Semin Dial 2006;19:323-328.

10 Reuter SE, Faull RJ, Evans AM: L-Carnitine supplementation in the dialysis population: are Australian patients missing out? Nephrology 2008;13:3-16.

11 Ahmad S, Robertson HT, Golper TA, Wolfson M, Kurtin P, Katz LA, Hirshberg R, Nicora R, Ashbrook DW, Kopple JD: Multicenter trial of L-carnitine in maintenance of hemodialysis patients. II. Clinical and biochemical effects. Kidney Int 1990;38:912-918.

-12 Brass EP, Adler S, Sietsema KE, Hiatt WR, Orland AM, Amato A: Intravenous L-carnitine increases plasma carnitine, reduces fatigue, and may preserve exercise capacity in hemodialysis patients. Am J Kidney Dis 2001; 37:1018-1028.

13 Rocchi L, Feola I, Calvani M, D’Iddio S, Alfarone C, Franscarelli M: Effects of carnitine administration in patients with chronic renal failure undergoing periodic dialysis, evaluated by computerized electromyography. Drugs Exp Clin Res 1986;12:707-711.

14 Albertazzi A, Spisni C, Del Rosso G, Palmieri PF, Rossini PM: Electromyographic changes induced by oral carnitine treatment in dialysis patients. Proc Clin Dial Transplant Forum 1980;10:1-6.

15 Fagher B, Cederblad G, Eriksson M, Monti M, Moritz U, Nilsson-Ehle P, Thysell H: L-Carnitine and haemodialysis: double blind study on muscle function and metabolism and peripheral nerve function. Scand J Clin Lab Invest 1985;45:169-178.

16 Feinfeld DA, Kurian P, Cheng JT, Dilimetin G, Arriola R, Ward L, Manis T, Carvounis CP: Effect of oral L-carnitine on serum myoglobin in hemodialysis patients. Ren Fail 1996;18:91-96.

17 Giovenali P, Fenocchio D, Montanari G, Cancellotti C, D’iddio S, Buoncristiani U, Pelagaggia M, Ribacchi R: Selective trophic effect of L-carnitine in type I and IIa skeletal muscle fibers. Kidney Int 1994;46:1616-1619.

-18 Vaux EC, Taylor DJ, Altmann P, Rajagopalan B, Graham K, Cooper R, Bonomo Y, Styles P: Effects of carnitine supplementation on muscle metabolism by the use of magnetic resonance spectroscopy and near-infrared spectroscopy in end-stage renal disease. Nephron Clin Pract 2004;97:c41-c48. 
19 Sietsema KE, Hiatt WR, Esler A, Adler S, Amato A, Brass EP: Clinical and demographic predictors of exercise capacity in end-stage renal disease. Am J Kidney Dis 2002;39:76-85.

20 Fatouros IG, Douroudos I, Panagoutsos S, Pasadakis P, Nikolaidis MG, Chatzinikolaou A, Sovatzidis A, Michailidis Y, Jamurtas AZ, Mandalidis D, Taxildaris K, Vargemezis V: Effects of L-carnitine on oxidative stress responses in patients with renal disease. Med Sci Sports Exerc 2010;42:1809-1818.

-21 Poggio R, Arazi HC, Giorgi M, Miriuka SG: Prediction of severe cardiovascular events by VE/VCO2 slope versus peak VO2 in systolic heart failure: a meta-analysis of the published literature. Am Heart J 2010;160:10041014.

22 Saval MA, Kerrigan DJ, Ophaug KM, Ehrman JK, Ketevian SJ: Relationship between leg muscle endurance and VE/VCO2 slope in patients with heart failure. J Cardiopulm Rehabil Prev 2010;30:106-110.

-23 Kinnula VL, Sovijarvi AR: Elevated ventilator equivalents during exercise in patients with hyperventilation syndrome. Respiration 1993;60:273-278.

-24 Abbiss CR, Nosaka K, Laursen PB: Hyperthermic-induced hyperventilation and associated respiratory alkalosis in humans. Eur J Appl Physiol 2007;100:63-69.

25 Cederblad G, Bylund A, Schersten JH: Carnitine concentration in relation to enzyme activities and substrate utilization in human skeletal muscles. Scand J Clin Lab Invest 1976;36:547-552. 